\title{
Experiences of nurse case managers within a central discharge planning role of collaboration between physicians, patients and other healthcare professionals: a sociocultural qualitative study
}

Authors: $\quad$ Jorun E. Thoma and Marion A. Waite

\begin{abstract}
:
Aims and objectives.

Purpose of this study was to gain knowledge of Nurse Case Managers' (NCM) experiences within the German acute care context of collaboration with patients and physicians in a discharge planning role. Further to learn about patients' assignment to the management of the NCMs. Explicitly, to explore critical incidences of interactions between NCM, patients and health care practitioner in discharge planning to understand the factor that contributes to effective collaboration.

Background and Purpose

The defined role of Nursing Case Manager (NCM) in many contexts is a patientcentred responsibility for a central task of discharge management of patients with complex physical and social needs. Some studies have indicated that the general impact of the role reduces readmission rates. Given the necessity to work interprofessionally to achieve a safe discharge little is known about how NCMs achieve this collaboratively.

Methods.

A qualitative case study within a German teaching hospital of NCMs (N=8). Data were collected through semi-structured interviews prompted by a critical incident technique and rigorously analysed through the lenses of sociocultural theory.

Results.

Consistent object being worked upon was a safe and effective discharge from hospital with a focus on patient advocacy. Significant themes were a self-value or recognition by others of professional expertise, reciprocal value on the capabilities of others thorough relational expertise and negotiation with patients and an identification of case trajectories.

Conclusion.

More continuity of NCMs' care and management, clarity of role and transparency to peers, physicians and other professionals would be beneficial in ensuring appropriate referral of complex patients to NCM responsibility.

Relevance to clinical practice

Clearer role description and benefit realisation of the NCM could be achieved by interventions that are interprofessional and focus on the tasks that matter from a collaborative perspective. This could lead to refinement of available indicators and policy developments.
\end{abstract}

\section{Keywords:}

discharge-planning; nurse case managers; inter-professional collaboration; patient advocacy; relational agency 


\section{INTRODUCTION}

Rising costs and limited means within international health care systems oblige health care providers to act economically. Parker (2012) Parker, and Yamamoto and Lucey (2005) contend that this has forced the reorganisation of such systems. The reasons for this are twofold, firstly, a growth of managed care due to capitation (Taylor, 1999; Yamamoto \& Lucey, 2005) and secondly the introduction of Diagnosis Related Groups (DRGs). This is a reimbursement system that originated from Australia and was implemented in six European countries, England, France, Germany, the Netherlands, Sweden, and most recently Switzerland. The underpinning idea was that hospital cases could be classified into DRGs and so be comparable in costs and characteristics between different hospitals and intended to increase transparency and improve efficiency (Busse et al., 2013). In addition to these financial and structural factors an increasing number of patients with multi-morbidity and chronic diseases bring an additional layer of complexity to these contexts (Carr, 2009; García-Fernández et al., 2014). Numerous scholars associate this with challenges for patient safety and implications for patient-centred care and discharge planning (Durbin, Hansen, Sinkowitz-Cochran, \& Cardo, 2006; Haas et al., 2014; Tytler, 2016; Zander, Dobler, \& Busse, 2013). Internationally, nurses have a key role in leading, managing and delivering these processes, which inevitably includes interprofessional working and listening to the patient voice in addition to the concerns of their carers. One such example is within the context of a German teaching hospital where discharge management for patients with complex situations and conditions is a task for Nurse Case Managers (NCMs). The central aim of discharge management is to 
provide patient-centred care on a safe continuum through the healthcare system and to reduce readmissions to hospital.(Bankston-White \& Birmingham, 2015; Carr, 2009; Taylor, 1999; Tytler, 2016; K. Zander, 2002). The purpose of this small-scale study was to examine the experiences, of the NCM within the context of a German teaching hospital and their discharge management role with a focus on the collaborative relationships between physicians, patients, and other health and social care professionals. This was through an analysis of the type of critical incidents and the actions, activities, intentions, interpretations of NCMs in relation to these.

\section{BACKGROUND}

\section{Tasks, scope, and outcomes of the NCMs role}

Within this article our focus was on NCMs role for management of discharge planning. This role is entitled variously within the literature. For example, 'orthopaedic discharge sister' (Tytler, 2016) 'medical-surgical nurses with competencies in care coordination and transition management' (Haas et al., 2014), 'discharge co-ordinator (Day, McCarthy, \& Coffey, 2009). The title 'discharge planning nurse' also appears as a job description in some contexts. The role can also be assigned to other health care workers such as social workers or case managers (Bisiani \& Jurgens, 2015). Parker (2012) portrays the NCM as a registered nurse with the authority and responsibility to care for high-risk patients and broker and coordinate this care. Additionally, NCMs have a role in communicating a proposed care plan to patients (Breslin, Hamilton, \& Paynter, 2014). Terra (2007) observed NCMs working across wards and departments and Yamamoto and Lucey (2005) have noted NCMs having responsibility for the conduction of multidisciplinary care rounds. In some contexts, NCMs provide a 9am-5pm service whereas in others 
NCMs are available and on-duty for 24 hours every day of the week (Venkatasalu, Clarke, \& Atkinson, 2015). Carr (2009) suggests that within intensive care units NCMs are seldom employed, however it does appear that NCMs work solely in acute care settings, which makes sense given the policy drivers internationally.

The outcomes, which impact on the reduction of readmission rates and length of stay, internationally are attributed to the NCM role (Breslin et al., 2014; Yamamoto \& Lucey, 2005). Whilst these findings are early indicators little is known about how NCMs achieve these potential outcomes through their collaborative activities. A further issue reported by Okoniewska et al. (2015) is that lack of role clarity of NCMs can lead to misinterpretation of the role by others. This is an important issue within collaborative working aimed at the best interests of the patient because referral of complex cases to the NCM is incumbent on other healthcare professionals (HCPs). It is crucial to firstly, identify complex cases and secondly, to appreciate the role of the NCMs in managing such cases. Thus, there is a need for research, which explores these issues and highlights the potential role that NCMs have in the management of safe and effective discharge planning.

\section{The German Context.}

To understand the NCM role in the historical, social, and cultural context of the German healthcare setting it is important to introduce the traditional hierarchy of a German teaching hospital. It is a physician-dominated organisation and in most hospitals physicians can occupy any one of six positions from the resident (position 1) to the head of department (position 6) (Jurkat, Raskin, \& Cramer, 2006). Traditionally, daily routine decisions such as treatment or discharge planning were decided by the attending physician (position 4). When the NCM role was 
implemented the intention was that the main collaborative partnership would be with the attending physician.

The position of the NCM was implemented at a University teaching hospital in Germany during 2012. These were implemented firstly in the Departments of Trauma and Orthopaedic Surgery and Neurology. Their hours of duty varied from 4 to 7.7 per day, depending on the number of patients. As a new role, the central task was to take an overall caring approach to patients with complex conditions focused upon their discharge planning needs. This involved steering and coordination of the patient process through advanced patient centred care as described by Atkins and Ersser (2008). An underpinning concept was patient safety. An NCM was allocated to those patients who had been identified as either complex from a physical or social perspective or a with complex medical condition or both. This allocation included patients with a pre-existing complex setting at home, who were caregivers themselves, or those patients who may appear complex but did not fit readily into guidelines. A checklist was available, which was developed locally and enabled a first screening on admission of a patient to assess whether their situation was complex or not. If the patient was assessed as not having a complex situation, then they were assigned to the responsibility of a staff nurse. Within the context skills for carrying out these initial assessments were largely attributed to the NCMs because of their tacit knowledge of these patient groups.

A central interdisciplinary standard for discharge management was implemented in the organisation. This standard is aligned with a German national expert standard for discharge management (German Network for Quality Development in Nursing, 
2015). An issue in the setting was lack of clarity around how and when patients were assigned to the responsibility of NCMs (or not) as appropriate when an NCM was unavailable to undertake the initial assessment. Anecdotally, there was a general feeling that appropriate case identification was insufficient in the absence of an NCM. The experiences of the first author who worked with the NCMs in one department, was that a central task of NCMs' daily routine involved collaboration with physicians, patients and other healthcare professionals in the discharge management process. Working on the tasks that mattered (Edwards, 2005; Hedegaard, Edwards, \& Fleer, 2011) meant dealing with the demands of the hospital, such as length of stay for which the physicians were accountable, and the concerns of patients. The attitudes of physicians with regards to length of stay and cost efficiency might have been influenced by changes in hospital reimbursement and was therefore also relevant for the NCMs as noted in other contexts (Powell, Doty, Casten, Rovner, \& Rising, 2016; Taylor, 1999; Yamamoto \& Lucey, 2005). This may have contradicted with the experiences of the NCMs who were confronted daily with the concerns of patients about their post-acute care after discharge and the need to serve as their advocate (Carr, 2009; Taylor, 1999; Venkatasalu et al., 2015). Thus, it was crucial to learn more about how NCMs dealt with collaborative working with regards to discharge planning. Collaboration is pivotal on the continuum of discharge planning between the demands of the hospital respective healthcare systems and the expectations of patients. It was of interest to learn how the NCMs were developing and coping with these responsibilities. Starting with the assumption that the patientcentred care approach that was being implemented incorporated more than discharge management, this study focused on exploring the NCM role in more 
depth. Therefore, an implication for primary research was evident and the following research question was identified:

What are the factors that contribute to effective collaboration between NCMs, patients, ward based nurses, physicians, and other HCPS in the context of their discharge planning role?

The aim of the study was to gain knowledge of how NCMs in the context experience collaboration with patients and physicians within their discharge planning role. Furthermore, the study aimed to learn how the patients become assigned to the management of the NCMs. A first objective was to identify NCMs' experiences of critical incidences of collaboration between patients, other nurses, physicians and health and social care practitioners (HCPs) in discharge planning and what can be learnt from these incidents to promote patient safety and further role development of the NCMs. A further objective was to understand the factors that contribute to effective collaboration between NCMs, patients, other nurses, physicians, and HCPs in the context of the discharge planning role.

\section{Collaboration as concept to understand a central point to enable safe discharge}

As the research was attempting to explore experiences and meaningfulness an interpretive approach of the social world (Bryman, 2012) was proposed. One theoretical lens that helped to frame the research and understand this collaborative 
aspect from the NCM perspective was Edward's $(2005,2015)$ concept of relational agency and expertise. Edward's premise is in part based upon Vygotsky's work (1987) (1987) on mediation, which is that actors interpret tasks that matter and work on them. Engagement with specialist practitioners enables the researcher to observe features of collaboration such as the specialist expertise that is distributed across the practice and setting. Within this theoretical framework the object is referred to as the complex task that practitioners work on collaboratively using the resources and expertise of others. This enables the actors to assert their core expertise and their relational agency and the resources that are used to work on complex problems. An example of the object within this research was the complex task which aimed for a safe discharge of hospitalised patients.

\section{METHODS}

\section{Research Design}

The research design was a qualitative study where the unit of analysis was a group of NCMs who practised within a German teaching hospital. Data were collected through a series of semi-structured interviews.

\section{Study setting}

The setting for the study was a large teaching hospital with approximately 1,600 beds and around 10,000 employees, of whom 2,900 were nurses. This organisation was hierarchically structured with regards to tasks as well as a defined relationship of authority and responsibility. 


\section{Data collection}

A qualitative approach comprising semi-structured interviews was used. A purposive sampling approach identified 35 NCMs employed by the organisation in this role through contact with their managers. During May 201531 NCMs were invited to participate in the study. An invitation letter was sent by mail to the potential participant's workplace address, which included information about the purpose of the study and how data was to be collected. 4 NCMs who worked in one specific department were excluded as the first author was directly involved in the original implementation of their NCM role. This aimed to avoid, or at least minimise, the bias of social desirability (Matthews, Baker, \& Spillers, 2003).

Ethics approval was obtained from the University where the first author was a master's student and the second author was the supervisor. Approval was also obtained from the organisation where data was collected.

Semi-structured interviews that were prompted by a critical incident technique (Flanagan, 1954) were conducted between June and September 2015. According to Edwards $(2005,2015)$ the implications for a study that is aiming to get at relational expertise is to examine the interplay between the dialectic of person and practice by following the actor, their activities in practice to get at their judgements, intentions, evaluations, interpretations, and actions. Hence the use of the critical incident technique, which aimed to go beyond data obtained from an interview alone, provides three core parts of information:

1) Through the participants' detailed description of an event or situation insights are gained into specific incidents; 
2) The concentration on the event enables an understanding of the action itself and reflected on the motivation;

3) Effectiveness of the actions are explored (Schluter, Seaton, \& Chaboyer, 2008).

\section{Sample}

Eight participants voluntarily agreed to take part in the research. The demographics of the sample were seven females and one male NCMs $(\mathrm{N}=8)$ aged $30-45$. Each research participant worked independently and within the context of their own ward or department. Informed consent was obtained in German and English so that the participants could clearly understand the conditions to which they were agreeing. Thus, informed consent was obtained prior to data collection. All the interviews took place at the hospital prior to or after the interviewees' shift, as convenient for them. Only the first author and one participant were present at a time. The interviews were audiotaped and transcribed verbatim. In line with the nature of some qualitative research, the interviewer stayed open to emerging aspects (Ziebland \& McPherson, 2006) during the interviews and kept a reflective diary to make sense of the emergent concepts. However, given the small sample size, the design and aims of the study and the conceptual framework a deductive approach was also taken during the subsequent analysis stage to ensure rigour. The inductive-deductive approach enables analytical generalisations to be made to other similar contexts (Yin, 2014). The participants were invited to describe two events within the context of their discharge planning role, one which went well and one, which did not go well from their perspectives. These incidents were not meant to date back more than two 
months to ensure accuracy of recall. As this study was conducted in Germany, the interviews were in German, transcribed in German by the first author for participant checking where transcripts were returned to participants for correction and/or comments and then translated into English by a native speaker.

\section{Analysis}

The data analysis was guided by an initial thematic analysis method (Braun \& Clarke, 2006) by researcher one (JT). Independently, researcher two (MW) assigned descriptive codes in NVivo (Richards, 2014) NVivo for MAC 11.4. This helped to identify the range and type of critical incidents and the actions, activities, intentions, interpretations, evaluations, and judgements of the NCMs in relation to collaboration with their peers, patients, ward based nurses and other HCPs in the context of their discharge planning roles. The data was further coded deductively in relation to the research question: "What are the factors that contribute to effective collaboration between NCMs, patients, ward based nurses, physicians and other HCPS in the context of their discharge planning role?"

\section{RESULTS}

\section{Descriptive analyses}

The NCMs identified that the overall goals of their discharge planning role were to achieve a safe and successful discharge for the patient whilst being their advocate (Table 1). It was evident that NCMs tacit knowledge could anticipate the structures that needed to be in place to plan for a safe and effective discharge and without exception collaboration was a key-mediating factor. 


\section{The NCMs perception of their main roles and tasks.}

To achieve these goals the NCMs described their main roles and tasks in practice as firstly, managing complex patients from admission to discharge and secondly, the main source of knowledge or point of contact for colleagues in the contexts such as ward based nurses, physicians, and HCPs. They felt that their tasks were related to the entire patient care process and had a key function with regards to patients' safety:

"Or viewing that globally and being involved from start to finish, I would say. Sometimes being involved with one patient, depending on which patient and what has to be done."

"At admission, I only have a very brief overview actually of what is already known of the patient. Then I have to look closely (...) And it's a criterion for me (...) if he already has diverse prior diagnoses and it's clear: he doesn't have only one problem, the patient, but there is more involved (...) then he's a complex patient for me."

"Well, basically from admission, that is starting at the admission interview to record the status, really at the admission interview. What care is currently needed at home? Or maybe in the family, small children, or the mother cared for at home." 
"I conduct the admissions interview, then I set up a care plan, evaluate that every day and arrange for discharge care as early as possible."

"Well, admitting the rather complex patients (..) to see what care is needed (...) and to see what care was running prior to hospitalization."

It would appear as though being involved in decision-making during the entire patient journey from admission promoted an anticipatory process to meet patient discharge needs.

\section{NCMs as the main interface within the context.}

Tacitly the NCM role had evolved to be a main point of contact for knowledge exchange about the patient with the other HCPs.

"it has sort of become established that we [NCMs] are a little bit like managers for the day-to-day operation of the ward."

"As I see it, the NCM is actually the absolute contact person for everyone, that is where all other professional groups make contact."

An obvious contradiction appeared to be the fact that NCMs perceive themselves as the main interface of expertise for complex patients, yet also felt that their role was non-transparent to others as there was not a full understanding of the NCM role:

"And, I think, that has to be made more transparent, to colleagues or even other professionals." 
The actions as described above involved collaboration as the main interface with ward based nurses, doctors and inter agency working with a broad range of internal and external HCPs such as social services, transitional nursing services, nursing homes, physiotherapists, and speech therapists. However, despite these collaborative actions the NCMs perceived that the scope of their role was nontransparent to others.

\section{Characteristics of critical incidents}

Characteristics of when incidents went well were as follows (Table 2); NCMs had developed thorough knowledge of the patients, and were effectively liaising with family members and so could plan a safe and effective discharge by negotiating with the patients and interagency working. There were also clear examples where the NCMs could assert themselves to change the potential course of events by negotiating with other HCPs such as the physicians. In some situations, the NCMs were unable to influence a safe and effective discharge and this was characterised by a lack of opportunity to assert themselves and lack of continuity when they were not on duty as ward/department based nurses had not developed the skills and expertise for effective discharge planning. Specific examples were:

- When patients are discharged within a day without any previous discharge planning;

- When the NCMs opinion was not heard by physicians;

- When colleagues intervened in a previously agreed discharge plan. 
Evidence of this was identified during the interviews on elicitation of an account of a critical incident where it was planned to discharge a patient at very short notice without any prior planning. The participant reported that the patient was told:

"you're going home tomorrow." I heard about it the following morning (...) and only because the doctors said offhand: "We don't know how he will get along at home." (...) Then I went to the patient and talked to him. ... He was really beside himself at that moment."

Not all participants could recall a critical incident where collaboration with other HCPs was not effective or did not lead to a good outcome for the patient.

Table 2

\section{Thematic analyses}

In inviting the participants to reflect on critical incidents it was possible to reach a deeper understanding of the NCM role from the perspective of effective collaboration and mediation within the discharge planning role. The following overall themes emerged:

1. The professional expertise of the NCMs was self- valued or valued by others hence patients were assigned to NCMs responsibility;

2. Valuing the expertise of others within collaborative discharge planning;

3. Negotiation with patients and recognition of their potential trajectories.

The professional expertise was self-valued or valued by others (Assignment to NCMs responsibility).

Case allocation for management by the NCMs themselves appeared to occur by specific tacit knowledge: 
"you simply know exactly which patients you have to take a closer look at, or where post-discharge care could be critical and because of the diagnosis. " Whilst a protocol referral pathway existed, lack of staff knowledge and shift rotation meant that this was not always operationalised, so usually NCMs managed the complex cases which they had self-allocated:

"I have to work on myself as well. When I come, the others make the end of shift report, and I prepare myself in advance, and when the end of shift report is finished, I have to take care myself."

Conversely, being valued and recognised by others was an important theme:

"But I have noticed that even the doctors refer to the NCM (pause) with respect to knowledge, too."

"and when there's a case where you say it won't work, the doctors always listen... it's good that this professional branch [the role] exists...NCM. The patients see it that way, and their families as well. They just have the feeling that there is someone in the ward who thinks about what's coming afterward, or what it was like before. And that gives them a feeling of more security."

The latter example illustrates the important role of the NCMs in terms of their longitudinal nature of their work and their historical view of the patient. 


\section{Valuing the expertise of others within collaborative discharge-planning}

Reciprocally, valuing the professional expertise and capabilities of others in the discharge process was an important factor for the process to go well. In fact, the participants frequently used this knowledge of the expertise of others as a strategy to lead and improve the course of events.

"Because you communicate at the same level... That is, really only with respect to the patient's care situation."

Furthermore, the NCMs stressed the premise of mutual understanding and valuing: "Just this understanding for the [various] sides.", or explicitly the doctor's side: "They don't look ahead, which I understand, they have enough else to do."

But the doctors don't always do that because they think it's good at the time, but they have instructions from many, many sides on how they should decide. And that's why you can't say "poor decision, won't work!“ But really say „I know why, but we still have to do something different" (...) Just this understanding for the [various] sides."

"And it's important too, for example, with physiotherapy, that's also important, and I'm the link there to hear how mobile is the patient now? What has been organized for home?"

“But talking to the doctor is, in fact, actually very important. Yes, it doesn't work without the doctor. I can't discharge the patient on my own authority. I 
need the doctor for that, and I need to talk to him, and often it's all rush-rush. Mornings during rounds, they have to go to early conference, so that means I have to be really well prepared, even for the rounds."

"The doctor's focus is more on the medical treatment ...

....and now care is not the doctor's main focus. But that's OK, that's why it's divided among various professional groups."

Clearly the NCMs relied on the distributed expertise of others where and when appropriate and operationalised strategies to maximise this expertise.

\section{Negotiation with patients and recognising their potential trajectories}

The previous examples illustrate the expertise of the NCMs regarding acquired knowledge of the histories of patients, however exposes a further contradiction between the wishes of the patient to go home as soon as possible versus the practical issues regarding safety and independence:

" And looking more closely, it turned out that she [the partner] only came once a week. It was understandable that she wanted to go home, to her own house. But we were concerned that she simply couldn't manage. The circumstances changed and you have to see the whole picture."

" But the wheelchair doesn't fit in the bathroom. You need someone to help you get out of the chair at the bathroom door and help you onto the toilet seat, 
for example. These are banal things, but they make it difficult to go home at the end."

"The longer you are in the ward, you simply know exactly which patients you have to take a closer look at, or where post-discharge care could be critical and because of the diagnosis."

"You have to recognize that possibly, for example, the patient is a dependent caregiver. That is, not he himself, but if his wife at home [needs care] We could see whether the social station could visit you once a day. To understand that it is maybe a temporary thing. And someone will only help me to overcome this "problem". That I can be independent again."

"and then I always ask first because I think a lot of patients have a little reluctance, if you just say someone from Social Services a lot will then maybe think of welfare or something like that. A lot of people don't like that, so I have to explain what I mean. And then it works out very well."

NCMs perceived that they were doing an important job for patient safety and wellbeing. The participant quotes suggest close observation of activities of daily living, an awareness of the social situation and sensitivities to the notion of requiring help and assistance on discharge. These factors appeared to be underpinned by close observation of patients and an intuitive awareness of the risks of discharging vulnerable patients. 


\section{DISCUSSION}

The overall results of the study suggest that the consistent object being worked upon was a safe and effective discharge from hospital within a focus on patient advocacy. Collaborative work with others was seen on a continuum between effectiveness and non-effectiveness, the latter leading to poorer outcomes for the patients. NCMs appeared to perceive different ways of coping with critical incidents whilst mediating between physicians and patients in discharge planning. The NCMs were the main interface with other HCPs for complex patients; it appeared imperative for the NCMs to manage the whole patient journey from admission to discharge for things to go well for the patients. The main conflict was lack of knowledge of other nurses who failed to refer complex patients to the NCMs, either because complexity was not identified or an incomplete understanding of the NCM's role in managing such patients leading to a lack of referral to their care.

\section{Collaboration with physicians}

Collaboration with physicians in the context of discharge planning was a central theme in the findings of this study. This contrasted with the slight attention given to this issue in the reviewed literature. Where this was successfully achieved the NCMs could value and employ the resources of physicians and other HCPs. This is most evident from the NCMs experiences of collaboration as being positive and effective. This enabled clear communication with patients and a systematic flow of information. In the study by Okoniewska et al. (2015) communication was identified: 
"as an important factor influencing an effective discharge process". Furthermore, successful collaboration can reduce or even prevent life threatening medical errors (Carr, 2007).

Returning to Edwards's notion of relational agency $(2005,2015)$ as a conceptual lens:

"Relational agency is a capacity to work with others to expand the object that one is working on and trying to transform by recognising and accessing the resources that others bring to bear as they interpret and respond to that object." (Edwards, 2015, p. 172)

Participants also saw a relationship between mediation with physicians and patients by an understanding of the motivations and the perspectives of all parties. For example, physicians needed the beds for new admissions alongside patients' desires to return home. Reciprocally, it was important for the physicians to appreciate the NCMs role as being supportive. This also involved being open to prompting from the NCMs on management issues such as correct documentation or safe and effective prescribing of medicines.

Edwards also draws on Middleton's concept of common knowledge (1996), which seeks to expose and recognise what is salient for others during the process of collaborative action. Middleton claims that common knowledge celebrates the difference between practitioners who are not trying to be the same, however little is known about how common knowledge is built. The assumption may arise that NCMs and physicians were still playing the 'nurses-doctor game' wherein nurses back up 
the decisions of physicians (Holyoake, 2011; Stein, 1967). In turn, this assumption could cloud the judgement of others who may not realise the importance of the developing role. Common knowledge may be crucial for the recognition of nursing practice as it develops at the boundaries of systems and practices such as NCM roles.

Edwards identifies two features of collaboration, relational agency as above and the recognition by practitioners of distribution of specialist expertise across practice. In these circumstances the practitioners apply their core expertise and expand the object being worked upon to improve outcomes. For this happen more consistently interventions may be required by the health care institution that are inter-professional in nature and focus on the tasks that matter from a collaborative perspective. Some participants did not evaluate ineffective collaboration as being critical but as a regular situation, which they can handle. This may relate to the findings of Bankston-White and Birmingham (2015) who highlighted that NCMs should be able to manage unexpected situations adequately. However, the importance of the findings of our study was getting at how the NCMs managed this.

\section{Main conflicts}

The sociocultural tools as developed by Edwards (2015), Hedegaard et al., (2011)(2011), and Middleton, (2011) on relational expertise and agency have helped to explore the experiences of NCMs in their discharge-planning role within the context of this research project. Some of the key issues where experiences of collaboration did not go well were a lack of continuity for discharge planning when the NCMs were not on duty. This was because of the lack of expertise of 
ward/department based nurses or a lack of understanding of the NCM role of other nurses, physicians and HCPs which led to lack of assignment to NCM care. Within the context this was also exacerbated by short service hours of the NCMs and consistent with other contexts Venkatasalu et al. (2015). An outcome was the way in which NCMs had to self-assign complex patients to their care by proactively identifying patients with complex conditions or in complex situations without a rubric or protocol for assessment. This issue is consistent with other researchers in similar contexts for example, Carr (2009), Terra (2007), and Yamamoto and Lucey (2005) in so far, as the case identification is done using tacit knowledge but not employing an assessment instrument.

\section{RELEVANCE TO PRACTICE (this section moved up from}

\section{conclusion)}

As the first author has a practice development responsibility for the implementation of the NCMs role within the context it was important to gain a better understanding of the collaborative aspect (NCM, physician and patient) of discharge planning so that it may be developed and sustained. Within the context, and similar areas of international practice, more dialogue, and opportunities for reflection through education and training may enable a better understanding of the NCMs role. Furthermore, effective ways in which to distribute the expertise more widely between existing nursing staff and develop novice awareness. Edwards (2015) describes this as the potential for the boundary zone where local expertise may be made explicit 
"We now need to know more about them by asking what goes on there to build the common knowledge that can mediate quick knowledge transfer between practitioners when they collaborate on complex problems" (Edwards, 2015, p. 35).

Relational expertise as a related concept describes how joint action between more than one practitioner on shared problem or object empowers two subjectivities and conceptual tools leading to expansion of interpretation on the problem. In the context of this study NCMs working jointly with physicians and other HCPs to achieve a safe discharge from hospital. Much of Edwards research on relational agency and relational expertise has been in children's services or school teacher development (Edwards, 2005, 2015). Her argument for the importance of this concept in these contexts is that the complexity of children's trajectories may mean that practitioners working alone on problems may miss vulnerability. In the context of the NCMs their core expertise identified the social, physical, and emotional trajectories for complex patients being discharged from hospital. Relational agency and expertise took account of potential vulnerabilities. This was particularly when collaboration with others worked well. Aligning these outcomes with future interventions such as joint opportunities between stakeholders to collaboratively expand the object being worked upon (safe and effective discharge) could lead to the refinement of the available indicators or develop an instrument that gives clear guidelines which is related to policy developments. This would benefit new and existing nursing colleagues and lead to expansive learning (Engeström, 2014) and promote information flow. A key recommendation from this study is to include physician and 
social workers in joint learning activities and development of discharge-planning policies, as they are, (together with nurses), the main stakeholders of discharge management. An important vehicle for expansion of the object is through interprofessional education owing to the potential to positively impact on patient outcomes (Reeves et al., 2008).

\section{LIMITATIONS}

The eight participants represented a selection of the departments where NCMs are allocated but not the entire organisation. In addition to this, the participants were volunteers and may have had different motivations for taking part in this study. The incidence of bias, such as social desirability, also must be considered. One reason why NCMs may have denied having experiences of ineffective mediation may lie in the fact that they associated researcher one with having a senior role, which was not the case as she was not in line management. Thus, their responses may have been affected by social desirability bias (Matthews et al., 2003) as they wanted to be seen to be doing their best. This may have indicated that they wanted to give the impression of having everything under control.

A further limitation is that the sample was relatively small and drawn from one single healthcare institution. Furthermore, the results are based on NCMs perceptions alone. Thus, there is scope for further research to encompass the views of all internal and external stakeholders involved in the collaborative process. This includes the patients, their carers, physicians, social workers, nursing colleagues and general practitioners. Further research methods such as ethnography could be employed, which gather further evidence on actors, their activities in practice to get at their 
judgements, intentions, evaluations, interpretations, and actions in addition to an analysis of the underlying activity systems, which influence these. This research focused on the qualitative aspects of the NCMs role, however there is scope for research that provides evidence of value and effectiveness with regards to clinical and financial outcomes. There is also potential scope to undertake interprofessional research alongside physicians on discharge planning for the benefit of patient safety. Within the sociocultural tradition this could be interventional and aims towards qualitative transformations for the actors concerned. This would address a current gap in the literature.

\section{CONCLUSION}

Within the international context of health care with rising costs and limited means, nursing roles such as NCMs have evolved to deal with processes such as discharge planning. This is aimed at addressing financial and clinical value but crucially focused on the safety and well-being of patients. This small-scale qualitative study within a German context focused upon the collaborative experiences of NCMs in their discharge-planning role. A critical incident technique was used to explore the judgements, intentions, evaluations, interpretations, and actions of the NCMs within their sociocultural context. The central and significant object being worked upon was a safe and effective hospital discharge for the patients and the main findings were that the NCMs played a central role for all stakeholders involved in this process. A key contradiction was lack of understanding of the NCM role by other nursing colleagues and some physicians, which led to poorer outcomes for patients. When collaboration worked well for the patient it was characterised by an understanding and value of the NCMs role and a mutual understanding of distributed expertise 
particularly between the NCMs and physicians, which may be conceptualised as relational agency. There is scope for more research with explores these collaborative processes from the perspectives of all stakeholders.

\section{Conflict of interest}

None 


\section{References}

Atkins, S., \& Ersser, S. (2008). Clinical Reasoning \& Patient-Centred Care. In J. Higgs, M. Jones, J. Loftus, \& N. Christensen, Clinical Reasoning in the Health Profession. (3rd ed.). Oxford: Elsevier Health Sciences.

Bankston-White, C., \& Birmingham, J. (2015). Case management directors: how to manage in a transition-focused world: part 1. Professional Case Management, 20(2), 63-7880. https://doi.org/10.1097/NCM.0000000000000078

Bisiani, M. A., \& Jurgens, C. (2015). Do Collaborative Case Management Models Decrease Hospital Readmission Rates Among High-Risk Patients?, 20(4), 188-196.

Braun, V., \& Clarke, V. (2006). Using thematic analysis in psychology. Qualitative Research in Psychology, 3(2), 77-101. https://doi.org/10.1191/1478088706qp063oa

Breslin, S. E., Hamilton, K. M., \& Paynter, J. (2014). Deployment of lean six sigma in care coordination: an improved discharge process. Professional Case Management, 19(2), 77-83-85. https://doi.org/10.1097/NCM.0000000000000016

Bryman, A. (2012). Social Research Methods. (4th ed.). Oxford: University Press.

Busse, R., Geissler, A., Aaviksoo, A., Cots, F., Häkkinen, U., Kobel, C., ... Quentin, W. (2013). Diagnosis related groups in Europe: moving towards transparency, efficiency, and quality in hospitals? BMJ (Clinical Research Ed.), 346, f3197.

Carr, D. D. (2007). Case managers optimize patient safety by facilitating effective care transitions. Professional Case Management, 12(2), 70-80-82. https://doi.org/10.1097/01.PCAMA.0000265340.72817.b5

Carr, D. D. (2009). Building collaborative partnerships in critical care: the RN case manager/social work dyad in critical care. Professional Case Management, 14(3), 121-132-134. https://doi.org/10.1097/NCM.0b013e3181a774c3 
Day, M. R., McCarthy, G., \& Coffey, A. (2009). Discharge planning: the role of the discharge co-ordinator. Nursing Older People, 21(1), 26-31; quiz 32. https://doi.org/10.7748/nop2009.02.21.1.26.c6871

Durbin, J., Hansen, M. M., Sinkowitz-Cochran, R., \& Cardo, D. (2006). Patient safety perceptions: A survey of lowa physicians, pharmacists, and nurses. American Journal of Infection Control, 34(1), 25-30. https://doi.org/10.1016/j.ajic.2005.08.008

Edwards, A. (2005). Relational agency: Learning to be a resourceful practitioner. International Journal of Educational Research, 3(43), 168-182. https://doi.org/10.1016/j.ijer.2006.06.010

Edwards, A. (2015). Recognising and realising teachers' professional agency. Teachers and Teaching, 21(6), 779-784. https://doi.org/10.1080/13540602.2015.1044333

Engeström, Y. (2014). Learning by Expanding. Cambridge University Press.

Flanagan, J. C. (1954). The critical incident technique. Psychological Bulletin, 51(4), 327. Retrieved from http://psycnet.apa.org/journals/bul/51/4/327/

García-Fernández, F. P., Arrabal-Orpez, M. J., Rodríguez-Torres, M. D. C., Gila-Selas, C., Carrascosa-García, I., \& Laguna-Parras, J. M. (2014). Effect of hospital casemanager nurses on the level of dependence, satisfaction and caregiver burden in patients with complex chronic disease. Journal of Clinical Nursing, 23(19-20), 28142821. https://doi.org/10.1111/jocn.12543

German Network for Quality Development in Nursing. (2015). Expert Standards in Nursing. Retrieved from http://www.dnqp.de

Haas, S. A., PhD, RN, FAAN, Swan, B. A., CRNP, ... CEN. (2014). Care Coordination and Transition Management Core Curriculum (First edition). American Academy of Ambulatory Care Nursing.

Hedegaard, Edwards, A., \& Fleer, M. (2011). Motives in Children's Development : CulturalHistorical Approaches. Cambridge: Cambridge University Press. 
Holyoake, D.-D. (2011). Is the doctor-nurse game being played? Nursing Times, 107(43), $12-14$

Jurkat, H., Raskin, K., \& Cramer, M. (2006). German medical hierarchy: the ladder to quality of life? The Lancet, 368(9540), 985-986.

Matthews, B. A., Baker, F., \& Spillers, R. L. (2003). How True Is True? Assessing Socially Desirable Response Bias. Quality and Quantity, 37(3), 327-335. https://doi.org/10.1023/A:1024420231961

Middleton, D. (2011). Analytic Challenges In Studying Professional Learning. In C. N. Candlin \& S. Sarangi (Eds.), Handbook of Communication in Organisations and Professions. Berlin, Boston: De Gruyter Mouton.

Okoniewska, B., Santana, M. J., Groshaus, H., Stajkovic, S., Cowles, J., Chakrovorty, D., \& Ghali, W. A. (2015). Barriers to discharge in an acute care medical teaching unit: a qualitative analysis of health providers' perceptions. Journal of Multidisciplinary Healthcare, 8, 83-89. https://doi.org/10.2147/JMDH.S72633

Parker, V. (2012). Nurse Case Managers: Perceptions of Their Engaged Activities. Capella University.

Powell, R. E., Doty, A., Casten, R. J., Rovner, B. W., \& Rising, K. L. (2016). A qualitative analysis of interprofessional healthcare team members' perceptions of patient barriers to healthcare engagement. BMC Health Services Research, 16. https://doi.org/10.1186/s12913-016-1751-5

Reeves, S., Zwarenstein, M., Goldman, J., Barr, H., Freeth, D., Hammick, M., \& Koppel, I. (2008). Interprofessional education: effects on professional practice and health care outcomes. The Cochrane Database of Systematic Reviews, (1), CD002213. https://doi.org/10.1002/14651858.CD002213.pub2

Richards, L. (2014). Handling Qualitative Data: A Practical Guide. SAGE. 
Schluter, J., Seaton, P., \& Chaboyer, W. (2008). Critical incident technique: a user's guide for nurse researchers. Journal of Advanced Nursing, 61(1), 107-114. https://doi.org/10.1111/j.1365-2648.2007.04490.x

Stein, L. (1967). The Doctor-Nurse Game. Arch Gen Psychiatry, 16(6), 699-703. https://doi.org/10.1001/archpsyc.1967.01730240055009

Taylor, P. (1999). Comprehensive nursing case management. An advanced practice model. Nursing Case Management: Managing the Process of Patient Care, 4(1), 2-10-13.

Terra, S. M. (2007). An evidence-based approach to case management model selection for an acute care facility: is there really a preferred model? Professional Case Management, 12(3), 147-157-159. https://doi.org/10.1097/01.PCAMA.0000271365.01171.b6

Tytler, B. (2016). Improving patient flow: role of the orthopaedic discharge sister. Emergency Nurse, 23(10). https://doi.org/10.7748/en.23.10.20.s22

Venkatasalu, M. R., Clarke, A., \& Atkinson, J. (2015). 'Being a conduit' between hospital and home: stakeholders' views and perceptions of a nurse-led Palliative Care Discharge Facilitator Service in an acute hospital setting. Journal of Clinical Nursing, 24(11-12), 1676-1685. https://doi.org/10.1111/jocn.12769

Vygotsky, L. (1987). The Collected Works of L.S. Vygotsky. In R. Rieber \& A. Carton (Eds.), The problems of General Psychology (Vol. 1). New York: Plenum Press.

Yamamoto, L., \& Lucey, C. (2005). Case management 'within the walls': a glimpse into the future. Critical Care Nursing Quarterly, 28(2), 162-178.

Yin, R. (2014). Case Study Research Design and Methods (5th ed.). Thousand Oaks: SAGE. Zander, B., Dobler, L., \& Busse, R. (2013). The introduction of DRG funding and hospital nurses' changing perceptions of their practice environment, quality of care and satisfaction: Comparison of cross-sectional surveys over a 10-year period. International Journal of Nursing Studies, 20, 219-229. 
Zander, K. (2002). Nursing case management in the 21st century: intervening where margin meets mission. Nursing Administration Quarterly, 26(5), 58-67.

Ziebland, S., \& McPherson, A. (2006). Making sense of qualitative data analysis: an introduction with illustrations from DIPEx (personal experiences of health and illness). Medical Education, 40(5), 405-414. https://doi.org/10.1111/j.1365-2929.2006.02467.x

\section{Table 1: NCM Goals}

\begin{tabular}{|c|}
\hline Goals: \\
\hline $\begin{array}{l}\text { Sometimes a patient has to stay a couple of days if home care is not organized or } \\
\text { there's no guarantee that he will be cared for." }\end{array}$ \\
\hline $\begin{array}{l}\text { "So, the patients don't have to go to the family doctor right away and say "They said I } \\
\text { need physiotherapy but I don't have a prescription for that." }\end{array}$ \\
\hline $\begin{array}{l}\text { We really could discharge him in good conscience (..) and send him home with all his } \\
\text { support equipment and a care service that came three times a day and attached the } \\
\text { antibiosis." }\end{array}$ \\
\hline $\begin{array}{l}\text { And then we can say what auxiliary equipment is really needed, Whether a walker, a } \\
\text { wheelchair, toilet chair, this or that, whatever." }\end{array}$ \\
\hline $\begin{array}{l}\text { "Because the treatment process has been completed. And now, so to speak, thanks } \\
\text { to your medication and further discussions, it‘s possible for the patient to not go into a } \\
\text { nursing home, but go home, go directly home..." }\end{array}$ \\
\hline $\begin{array}{l}\text { That wound healing is looked after, that nutrition is appropriate, it could happen, that } \\
\text { she is under nourished because she can't cook for herself or do the shopping." }\end{array}$ \\
\hline
\end{tabular}


Table 2: Critical Incidents

\begin{tabular}{|c|c|}
\hline When collaboration goes well & When collaboration does not go well \\
\hline $\begin{array}{l}\text { [He] was actually distraught, what should } \\
\text { he do? How was he to get through the } \\
\text { week? Since he still had trouble walking. } \\
\text { Then I first met with the doctors and said } \\
\text { "We have to find a different solution. I can } \\
\text { try to set up various things, like social } \\
\text { service at home, so that he gets his food. } \\
\text { That someone does the shopping or he } \\
\text { gets dinner." Then we contacted Social } \\
\text { Services, to see whether the rehab could } \\
\text { be rescheduled (...) and (...) after all these } \\
\text { offices were involved, I talked to the patient } \\
\text { again and again and told him "We will take } \\
\text { care of things. You are not going to go } \\
\text { home and suddenly have no idea how you } \\
\text { down. }\end{array}$ & 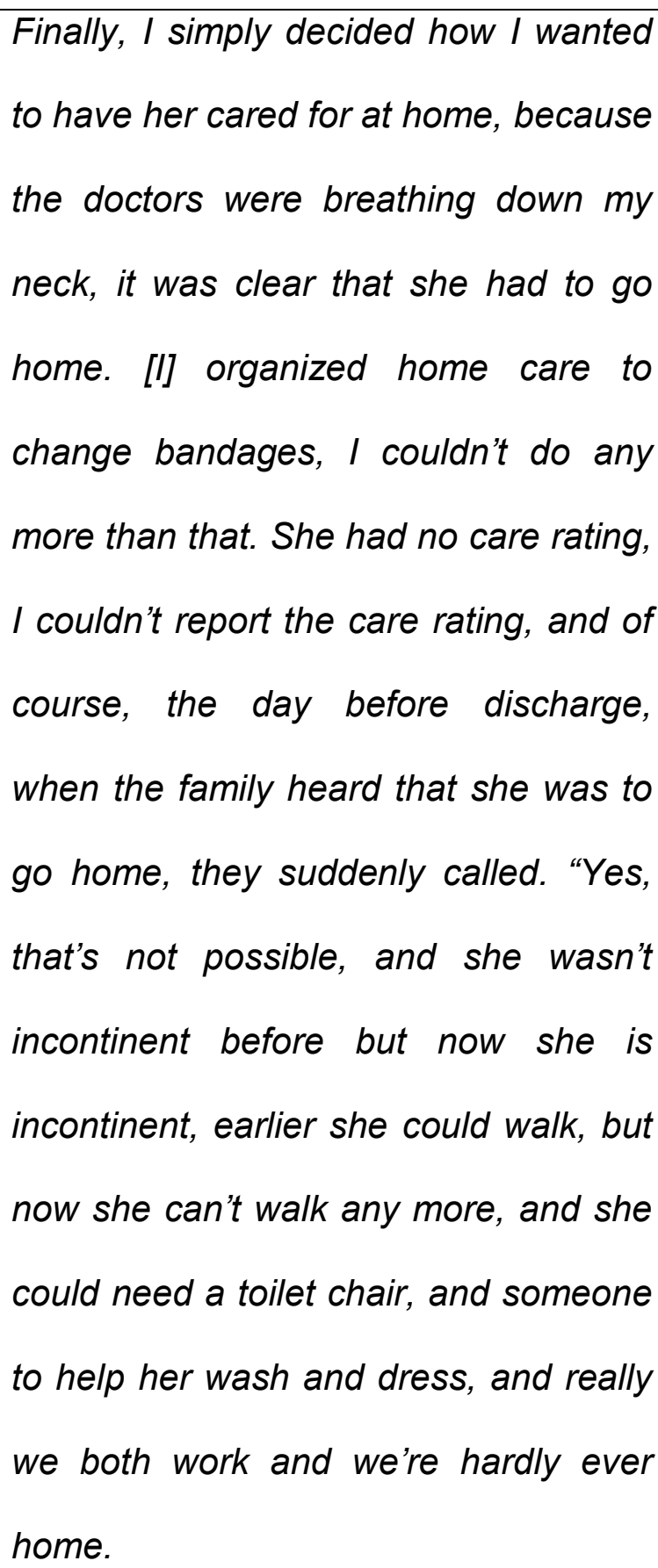 \\
\hline
\end{tabular}


